\title{
An Enzyme Linked Immunosorbent Assay (ELISA) for Detection of Antibodies to the Koi Herpesvirus (KHV) in the Serum of Koi Cyprinus carpio
}

\author{
Mark A. Adkison ${ }^{1}$, Oren Gilad ${ }^{2}$ and Ronald P. Hedrick ${ }^{1 *}$ \\ ${ }^{1}$ Department of Medicine and Epidemiology, School of Veterinary Medicine, \\ University of California, Davis, CA 95616, USA \\ ${ }^{2}$ Cancer Center, University of California, Sacramento, CA 95817, USA
}

(Received January 26, 2005)

\begin{abstract}
An enzyme linked immunosorbent assay (ELISA) detected the presence of anti-koi herpesvirus (KHV) antibodies in the serum of koi or colored carp (Cyprinus carpio) following either natural or experimental exposures to KHV. Concentrations of anti-KHV antibodies were detected at serum dilutions as great as 1:62,500 in a population of koi kept in virus-free water for 1 year following a naturally occurring outbreak due to KHV. At serum dilutions less than 1:2,500 cross reactions with a second herpes-like viral agent Cyprinid herpesvirus 1 (CyHV-1) was detected in serum from both experimentally and naturally KHV exposed koi. Passive immunization by administration of anti-KHV antibodies from koi recovered from previous virus infections to naive koi provided only partial and transient protection to waterborne challenges with KHV. Koi that maintained high levels of serum anti-KHV antibodies after 1 year in virus-free water are deemed as suspect carriers of the virus. The identification of suspect carriers by screening of koi and common carp populations, including potential broodstocks, with the KHV ELISA should improve the ability to control this important viral pathogen.
\end{abstract}

Key wards: koi herpesvirus, KHV, Cyprinus carpio, ELISA, antibody, koi

The koi herpesvirus (KHV) was first reported as the cause of mass mortality among koi and common carp (Cyprinus carpio) in Germany, Israel and the USA in 1998 but retrospective studies indicate the disease was present in common carp in the UK as early as 1996 (Bretzinger et al., 1999; Hedrick et al., 1999; Hedrick et al. 2005; Way et al. $\left.{ }^{* 1}\right)$. The worldwide movements of koi have presumably contributed to the spread of the virus which has now been recognized in several additional European countries, Indonesia, South Africa, Thailand, Taiwan, Japan and most likely China and Malaysia (Haenen et al., 2004; Tu et al., 2004; Sano et al., 2004).

The virus was isolated from koi originating from Israel and the USA in 1998 and based upon morphologic

\footnotetext{
* Corresponding author

E-mail: rphedrick@ucdavis.edu

*1 Way, K., N. D. Beevers, C. L. Joiner, C. B. Longshaw, S. St-Hilaire, D. M. Stone, K. L. Denham and P. F. Dixon (2004): Koi herpesvirus in the UK: Detection in archive tissue samples and spread of the virus to wild carp. Abstract $6^{\text {th }}$ International Symposium on Viruses of Lower Vertebrates, Hakodate, Japan, September 2004.
}

and biologic properties was designated as KHV by Hedrick et al. (2000). Recent genomic sequence comparisons by Waltzek et al. (2005) confirm that KHV is related to a larger group of fish herpes-like viruses in the family Herpesviridae and more specifically to Cyprinid herpesvirus 1 (CyHV-1) from koi and common carp and Cyprinid herpesvirus 2 (CyHV-2) from gold fish (Carassius auratus). Based upon these genetic relationships and that the fish hosts are all restricted to the family Cyprinidae, a proposal to formally designate KHV as Cyprinid herpesvirus 3 has been submitted (Waltzek et al., 2005). Designation of the virus as Cyprinid herpesvirus 3 (CyHV-3) supplants previous designations for the virus including descriptions of $\mathrm{KHV}$ in Israel as carp interstitial nephritis and gill necrosis virus (CNGV) by Ronen et al. (2003), Pikarsky et al. (2004) and Hutoran et al. (2005).

Additional properties of KHV have been described including the important role of temperature on experimental infections of koi and koi cell cultures, major target tissues during infection and improved detection methods for the virus and viral DNA (Gilad et al., 2002, 2003 and 
2004; Ronen et al., 2003; Perelberg et al., 2003; Pikarsky et al., 2004). Both natural and experimental infections of koi with KHV at permissive water temperatures $16-28^{\circ} \mathrm{C}$ result in high mortality $(70-100 \%)$ over a course of 7-21 days (Gilad et al., 2003). Fish that survive infection, including those subjected to elevated water temperatures following infection, develop some or complete resistance to re-infection (Gilad et al., 2003; Ronen et al., 2003). The basis of this resistance is not known but anti-virus serum antibodies have been shown to increase in survivors post exposure to the virus (Ronen et al., 2003). Tests that detect anti-KHV antibodies are thus important for evaluations of the potential immune status and as an indicator of prior exposure to the virus.

Detection of KHV during acute episodes of disease is possible by isolation of the virus using the KF-1 cell line and by one of several PCR assays that detect viral DNA directly from fish tissues (Gilad, et al. 2002; Gray, et al., 2002; Yuasa et al., 2005). Detection of KHV or viral genomic DNA has been difficult beyond 64 days post initial exposure even with highly sensitive quantitative PCR approaches (Gilad et al., 2004). Fish that survive infection are viewed as potential carriers and presumably their movements in international trade have spread the virus.

In the current study we describe an enzyme linked immunosorbent assay (ELISA) capable of detecting antiKHV antibodies in the serum of koi for periods up to 1 year from their last known exposure to the virus. The ELISA allows non-lethal sampling of individual or populations of koi to assess prior exposure and suspect carrier status in the absence of direct detection of infectious virus or viral DNA. In addition, the ability of anti-KHV serum to protect passively immunized koi later challenged with $\mathrm{KHV}$ was evaluated.

\section{Materials and Methods}

\section{Virus production and purification}

The virus isolate (KHV-I) used in this study was obtained from adult koi experiencing mass mortality in Israel in 1998 (Hedrick et al., 2000). The virus was propagated in the KF-1 cell line in minimal essential medium (MEM) supplemented with $7.5 \%$ fetal bovine serum (FBS - Hyclone), 50 IU penicillin/mL, $50 \mu$ g streptomycin/ $\mathrm{mL}$ and $2 \mathrm{~mm}$ L-glutamine as described previously by Hedrick et al. (2000). The concentration of FBS in the growth medium was reduced to $2 \%$ (v/v) (MEM-2) prior to virus inoculation and cells were placed at $20^{\circ} \mathrm{C}$ for incubation until complete cytopathic effects (CPE) were observed. Cyprinid herpesvirus 1 (CyHV-1) was originally isolated from koi in Japan (Sano et al., 1985a) and it was also propagated in KF-1 cells under the same conditions described for KHV. When needed for ELISA antigen or in blotting procedures, both viruses were puri- fied as previously described by Gilad et al. (2002).

\section{Fish}

The koi in this study were from four sources representing a local producer and retailer (Supplier 1), a second local retailer (Supplier 2), a population held in Germany (Supplier 3) and a producer (Supplier 4) who maintains and breeds fish in dechlorinated municipal water in fiberglass tanks. Fish ranged from $20 \mathrm{~g}$ to $2 \mathrm{~kg}$ in weight and in age from approximately $10 \mathrm{mo}$ to $>2$ years. Groups of koi from Supplier 1, 2 and 4 were transported live to the University of California at Davis (UCD) Fish Health Containment Laboratory where they were held in variably sized aquaria ranging in capacity from 130 to $650 \mathrm{~L}$ that received flow through well water at controlled temperatures of $19-23^{\circ} \mathrm{C}$. Fish were fed once daily at $1-2 \%$ of body weight with a commercial trout ration. Koi from Supplier 3 were bled, serum collected and sent from the laboratory in Germany to the UCD laboratory for ELISA analysis. Additional information on fish sampled from each of the suppliers is provided below.

Three groups of koi were obtained from Supplier 1 who is a producer and retailer of koi for the local ornamental fish market. One group (S1-1) of 600 fish was approximately $10 \mathrm{mo}$ in age and ranged in size from 20 $50 \mathrm{~g}$ and came directly from a pond on the farm that showed no signs of KHV infection in 2003. This group was approximately 1.5 year in age and had been held in the UCD laboratory for approximately 6 mo in flow through well water at $19-23^{\circ} \mathrm{C}$ when they were used for the passive immunity trial described below. Approximately 60 of these fish were tested on several occasions during the 6 mo prior to the passive immunity trial for evidence of KHV by PCR (as controls for other KHV experiments) and no evidence for viral DNA was detected. Also, ELISA evaluations for 41 fish examined after 6 mo post transfer to the laboratory were examined for evidence of anti-KHV antibodies.

A second group (S1-2) of 400 koi of similar size and age to S1-1 were obtained in 2004 again from a second pond with no evidence of KHV infection. The fish were transported to the UCD laboratory and held under conditions described previously. A total of 40 fish were examined for presence of anti-KHV antibodies by ELISA 2 wk following transfer the laboratory. A third group (S1-3) of $300 \mathrm{koi}$, ranging in size from $50-200 \mathrm{~g}$ and approximately 1 year in age were also obtained in 2004 from the retail area where various groups of fish are mixed and held in a recycled water system $\left(21-25^{\circ} \mathrm{C}\right)$ prior to sale. These fish were undergoing an active KHV outbreak at the time of transport to the UCD laboratory. The fish were held in the UCD laboratory in a $650 \mathrm{~L}$ aquarium receiving $19^{\circ} \mathrm{C}$ flow through well water. The cumulative mortality over the following week was $75 \%$. A total of 71 fish surviving at 1 wk post 
transport were bled and the serum tested for the presence of anti-KHV antibodies by ELISA. An additional 10 fish from this group were examined 47 days later for evidence of anti-KHV antibodies by ELISA.

A group (S2-1) of mixed sizes $(50 \mathrm{~g}-500 \mathrm{~g}$ ) and age koi ( 1 - > 2 yr) was obtained in 2004 from Supplier 2 who was a second local retailer. The supplier had received a shipment of koi from Japan that upon arrival immediately underwent an outbreak of KHV. Water temperature in the partially recycled system ranged from 21$25^{\circ} \mathrm{C}$ during the outbreak. Approximately $6 \mathrm{wk}$ following the initiation of the outbreak, mortality ceased and a group of 221 fish were transported to the UC Davis laboratory where they were held under conditions identical to those described for fish from Supplier 1. After $1 \mathrm{wk}$ in the laboratory, 64 fish were bled and the serum was tested by ELISA.

Supplier 3 provided koi (S3-1) that had been shipped to a farm in Germany from Israel. The fish ranged in size from 100-200 $\mathrm{g}$ and were approximately 2 years in age at the time of sampling. These koi were survivors of a KHV outbreak experienced following arrival at the farm. Fish surviving the outbreak were transported to the Fish Health Laboratory at the University of Munich where they were held in $500 \mathrm{~L}$ aquaria receiving dechlorinated tap water heated to $21^{\circ} \mathrm{C}$ for approximately 1 year prior to collection of the serum analyzed by ELISA. A total of 17 fish from this group were examined.

Supplier 4 has provided live koi to the UCD laboratory for the past 4 years and these fish have been consistently free of any evidence of KHV. Serum samples were obtained from both the controls and KHV-exposed fish from a trial to evaluate virus replication by PCR at a water temperature of $28^{\circ} \mathrm{C}$ (Gilad et al., 2004). At 64 days post virus exposure, 8 surviving koi and 8 controls held under the same conditions but not exposed to virus were bled and the serum examined for the presence of anti-KHV antibodies by ELISA and western blotting. The fish were from $200-300 \mathrm{~g}$ in size and approximately 2 year in age at the time of sampling. An additional group of 8 koi from S1-1 free of anti-KHV antibodies received intraperitoneal injections with 100 tissue culture infectious doses $\left(\mathrm{TCID}_{50}\right)$ of $\mathrm{CyHV}-1$ grown in $\mathrm{KF}-1$ cells. After injection, the koi were held in a $130 \mathrm{~L}$ aquarium receiving $21^{\circ} \mathrm{C}$ well water. After $8 \mathrm{wk}$ blood was collected from each fish and the serum separated for western blot analyses with $\mathrm{CyHV}-1$ and KHV proteins.

\section{Koi serum and plasma}

Depending on the size of the fish, serum or plasma was collected for ELISA. With smaller fish $(<100 \mathrm{~g})$, blood was collected from the caudal vessels into heparinized microhematocrit tubes, centrifuged and the plasma collected. With larger fish, blood was collected in untreated microhematocrit tubes, vacutainers or syringes, allowed to clot and the serum collected by centrifugation. Serum and plasma were stored at $-20^{\circ} \mathrm{C}$ prior to analysis by ELISA for the presence of anti-KHV antibodies.

The ELISA was developed and optimized similar to the procedures described by Case et al. (1983). To optimize each step of the procedures a positive serum pool was created from the serum of $7 \mathrm{koi}$ ranging in size from $0.5-1 \mathrm{~kg}$. The sera were obtained from koi which had survived a bath exposure to KHV that resulted in an $80 \%$ cumulative mortality (Gilad et al., 2003). The sera were obtained from survivors at 64 days post initial exposure to KHV. The serum negative pool was made from 7 control fish from the same group of koi used for the $\mathrm{KHV}$ exposures for the positive serum pool but never exposed to the virus. Concentrations of each of the following reagents for the ELISA was optimized: coating antigen consisting of gradient purified KHV (Gilad et al., 2002), WCI 12 mouse anti-carp Ig monoclonal antibody (mab) supernatant (Rombout et al., 1993), biotinylated goat anti-mouse IgG (Kirkegaard \& Perry) and the horseradish peroxidase (HRP)-streptavidin (SA) conjugate (Kirkegaard \& Perry). Optimal conditions were identified by individually titrating each reagent and determining the concentration that generated the maximum positive to negative $(P / N)$ ratio.

The ELISA plates (Falcon) were coated with $50 \mu \mathrm{L}$ per well of purified virus $(2 \mu \mathrm{g} / \mathrm{mL})$ in $0.1 \mathrm{M}$ carbonate buffer, $\mathrm{pH} 9.6$ for $12 \mathrm{~h}$ at $15^{\circ} \mathrm{C}$. After blocking the wells with $2 \%$ non-fat dried milk in Tris-buffered saline (TBS) (50 mm Tris, $1 \mathrm{~mm}$ EDTA, $150 \mathrm{~mm} \mathrm{NaCl}, \mathrm{pH}$ 8.0) for $1 \mathrm{~h}$ at $21^{\circ} \mathrm{C}, 50 \mu \mathrm{L}$ per well of dilutions of koi serum were added and incubated for $2 \mathrm{~h}$. The plates were washed 5 times with TBS with $0.1 \%$ Tween-20 (TTBS) and incubated for $1 \mathrm{~h}$ at $21^{\circ} \mathrm{C}$ with $50 \mu \mathrm{L}$ per well of $\mathrm{WCI} 12$ mouse anti-carp Ig tissue culture supernatant diluted 1:25. The plates were washed 5 times with TTBS and incubated for $1 \mathrm{~h}$ at $21^{\circ} \mathrm{C}$ with $50 \mu \mathrm{L}$ per well of affinity purified biotin labeled goat anti-mouse IgG antibody at $0.5 \mathrm{mg} / \mathrm{mL}$ diluted 1:800. Following five washes, plates were incubated for $30 \mathrm{~min}$ at $21^{\circ} \mathrm{C}$ with $50 \mu \mathrm{L}$ of HRP-SA diluted 1:500. The plates were washed 9 times and the color reaction was initiated by addition of $100 \mu \mathrm{L}$ per well of 3,3',5,5' - tetramethyl benzidine (TMB) $(50 \mu \mathrm{g} / \mathrm{mL}$ TMB in $50 \mathrm{~mm}$ citric acid buffer, $\mathrm{pH} 4.8$, and $0.01 \%$ $\mathrm{H}_{2} \mathrm{O}_{2}$ ). After $15 \mathrm{~min}$ at $21^{\circ} \mathrm{C}$, color development was arrested by adding $50 \mu \mathrm{L}$ per well of $1 \mathrm{M} \mathrm{H}_{2} \mathrm{SO}_{4}$ and the optical densities (O.D.) determined with a Bio-Tek Ceres 900HDi ELISA reader (Bio-Tek Instruments, Inc.) at a wavelength of $450 \mathrm{~nm}$. All dilutions of koi serum, WCI 12 mab, biotinylated goat anti-mouse and HRP-SA were made in TBS with $0.05 \%$ Tween-20 and $1 \%$ non-fat dried milk (TTBS-NFDM). All washes were with TBS containing $0.1 \%$ Tween-20. 


\section{Western Blotting}

Western blots with gradient purified KHV and CyHV1 were used to demonstrate the protein specificities of the anti-KHV and anti-CyHV-1 antibodies in koi serum. Proteins from purified KHV and CyHV-1 were separated by SDS-PAGE in a $10 \%$ or $12 \%$ acrylamide gel under reducing conditions as described by Gilad et al. (2002). Viral proteins were then transferred to Immobilon $\mathrm{P}$ membrane (Millipore) using a transphor wet blotting apparatus (BioRad). A strip of the membrane containing molecular weight markers and viral proteins was stained with $0.1 \%$ amido black in $40 \%$ methanol and $10 \%$ acetic acid for total protein determinations. Unstained strips were blocked for immunoblotting with $2 \%$ nonfat milk in TBS for $1 \mathrm{~h}$. Koi serum was diluted in TTBS-NFDM, added to the strips and incubated for 2 h. The strips were washed 3 times for $5 \mathrm{~min}$ and then WCl 12 mab tissue culture supernatant was added to the strips. After $1 \mathrm{~h}$ at $21^{\circ} \mathrm{C}$, the strips were washed with TTBS and alkaline phosphatase coupled to goat antimouse IgG (Sigma) in TTBS-NFDM was added. The blots were washed 4 times for $5 \mathrm{~min}$ in TTBS followed by 2 washes for 5 min each in TBS. The color reaction was visualized by staining with BCIP/NBT substrate (Sigma).

\section{Passive immunity trial}

A total of 60 juvenile koi $(10 \mathrm{~g})$ were divided into 6 equal groups $(n=10)$ each held in $130 \mathrm{~L}$ aquaria receiving flow through water at $23^{\circ} \mathrm{C}$. Three groups of koi received $0.1 \mathrm{~mL}$ of a pooled serum sample (positive serum) from 10 koi that were survivors of an experimental exposure to KHV in the laboratory (Gilad et al., 2003). Three other groups received $0.1 \mathrm{~mL}$ injections of a pooled serum sample from 10 additional koi from the same source but not exposed to KHV (negative control serum). Two groups of koi receiving the positive serum and two groups receiving the negative serum were then challenged by KHV propagated in the KF-1 cell line and then added to aquarium water to a concentration of 11 $\mathrm{TCID}_{50}$ per $\mathrm{mL}$. The remaining two groups received an equal volume of cell culture medium from the KF-1 line. After $1 \mathrm{~h}$, water flow was resumed to all aquaria which were observed twice daily for dead fish for $24 \mathrm{~d}$ when the study was terminated.

\section{Results}

\section{ELISA development}

For the ELISA development, both positive and negative serum pools were used to determine the optimal conditions for the assay. Optimal reagent concentrations were determined by calculating the reagent concentration that produced the highest $\mathrm{P} / \mathrm{N}$ ratio for each step. The optimal serum concentration that provided the highest $\mathrm{P} / \mathrm{N}$ ratio was $1: 500$ or 1:2500. We used these two serum dilutions of our positive and nega- tive serum pools for all subsequent reagent titrations and $\mathrm{P} / \mathrm{N}$ ratio determinations. From these titrations the following optimal concentrations of each reagent for the ELISA was determined; purified KHV coating antigen, 2 $\mathrm{mg} / \mathrm{mL}, \mathrm{WCl}-12$ mouse anti-carp $\mathrm{Ig}, 1: 25$, biotin labeled goat anti-mouse antibody $(0.5 \mathrm{mg} / \mathrm{mL})$ diluted to $1: 800$ and HRP-SA $(0.5 \mathrm{mg} / \mathrm{mL})$ diluted to $1: 500$. The $\mathrm{WCl} 12$ mouse anti-carp Ig was tissue culture supernatant and each batch was tested individually. All subsequent ELISA utilized these reagent concentrations with times for each step as indicated previously. Additionally, each plate used in all assays contained both a positive and negative serum control from which O.D. values for each test sample could be expressed as a \% of the positive control. The frequency or number of fish in the group at each \% of the positive control serum (reactivity)s were plotted or alternately O.D. values were shown for each serum dilution $(1 / x)$ for each individual fish. Optical density values considered as indicating the presence of anti-KHV antibodies were found in serum dilutions as great as 1:62500 with the positive control serum pool.

\section{ELISA of exposed and control fish}

Koi from Supplier 1 that were from farm ponds in both 2003 (S1-1) and 2004 (S1-2) that had no evidence of KHV infections were found to have little anti-KHV antibody in their serum (Fig. 1). All but 4 fish in these two groups had O.D. values that were below $10 \%$ of that for the positive control. Smaller lots of fish from both of these groups used as controls in several other KHV studies that were analyzed by PCR and ELISA provided additional evidence that they were a population with little or no exposure to KHV. A third group (S1-3) of koi obtained from the retail area of Supplier 1 that was undergoing a KHV outbreak contained numerous fish with O.D. values from 10 to $95 \%$ that of the positive control (Fig. 2). An increased number of anti-KHV positive fish were found upon examination of 10 fish from this same group 47 days later with all fish at O.D. values of

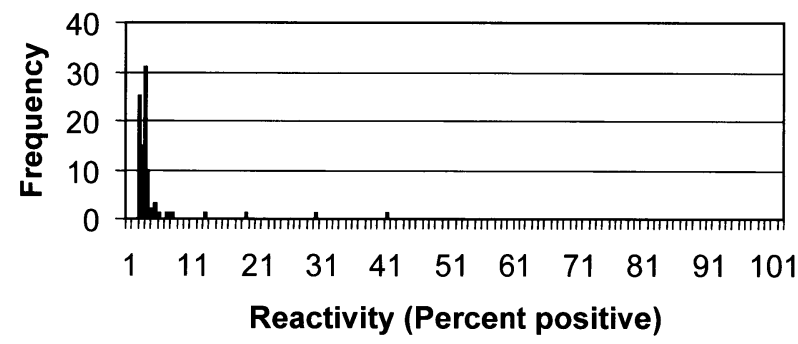

Fig. 1. Enzyme-linked immunosorbent assay (ELISA) detection of anti-koi herpesvirus (KHV) antibodies in the serum of two populations (S1-1 $n=40$ and S1-2 $n=$ 41) of koi from two ponds with no evidence of KHV disease. Frequency or number of fish at that ELISA value for each serum sample is expressed as a percent of the positive control included in each assay. 


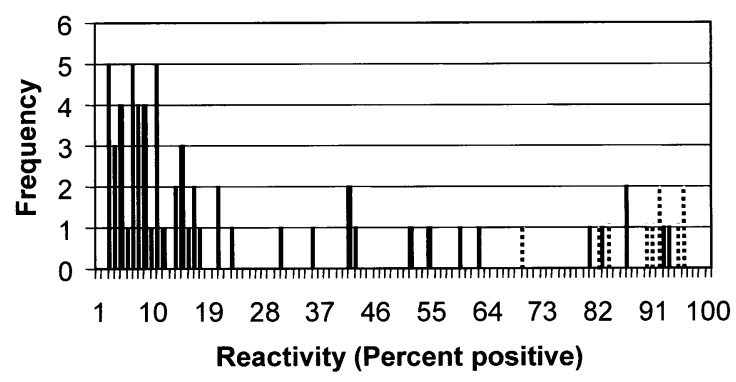

Fig. 2. Enzyme-linked immunosorbent assay (ELISA) detection of anti-koi herpesvirus (KHV) antibodies in the serum of a population (S1-3 $n=71$ ) of koi from the retail area of Supplier 1 that were in the early stages of an outbreak due to KHV and from koi from the same group $(S 1-4 n=10)$ sampled 47 days later. Note: black bars, during outbreak; dotted bars, 47 days later. Frequency or number of fish at that ELISA value for each serum sample is expressed as a percent of the positive control included in each assay.

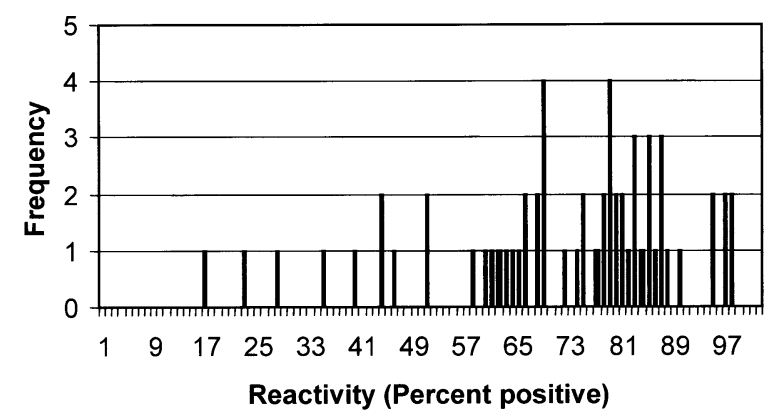

Fig. 3. Enzyme-linked immunosorbent assay (ELISA) detection of anti-koi herpesvirus (KHV) antibodies in the serum of a population $(S 2-1 n=64)$ of koi from a retailer (Supplier 2) that were examined 6 wk after recovery from a KHV outbreak. Frequency or number of fish at that ELISA value for each serum sample is expressed as a percent of the positive control included in each assay.

$>70 \%$ that of the positive control (Fig. 2).

Koi from Supplier 2 (S2-1) were survivors of a recent KHV outbreak that were examined approximately 6 wk following the cessation of mortality. Most fish in this group had O.D. values of $>60 \%$ that of the positive control with many fish clustering between 70 and $89 \%$ of the positive control (Fig. 3).

Serum from a group of 14 fish examined from Supplier 3 (S3-1) demonstrated a similar distribution of O.D. values to that from S2-1 with all fish but one at $>40 \%$ of the positive control serum (Fig. 4). An examination of these sera as tested by ELISA with both KHV and CyHV1 as coating antigens provided the first evidence of shared antigens between the two virus agents (Fig. 5). At serum dilutions of 1:20 to 1:500 there were substantial cross reactions with CyHV-1 as O.D. values reached up to $80 \%$ of the positive control (KHV) serum. The extent of cross reaction of the serum with CyHV-1 antigen was reduced or eliminated at serum

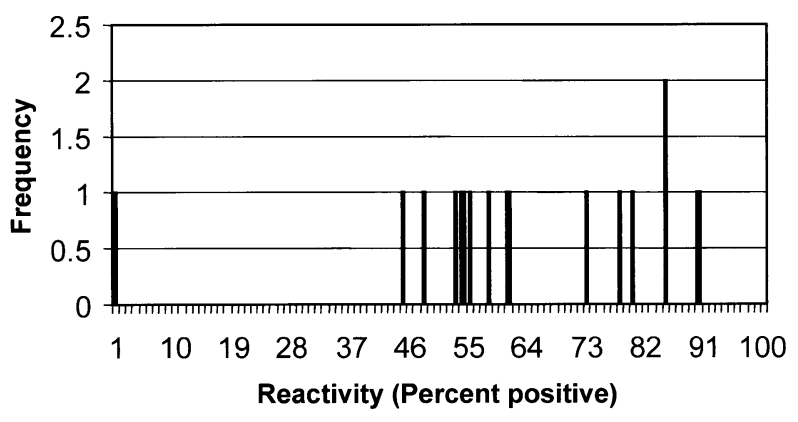

Fig. 4. Enzyme-linked immunosorbent assay (ELISA) detection of anti-koi herpesvirus (KHV) antibodies in the serum of a population (S3-1 $n=17$ ) of koi from Germany that had been held in dechlorinated municipal water for $1 \mathrm{yr}$ following recovery from a KHV outbreak. Frequency or number of fish at that ELISA value for each serum sample is expressed as a percent of the positive control included in each assay.

dilutions of 1:2500 or greater (Fig. 5).

Serum from koi from Supplier 4 (S4-1) were obtained from an experimental and a control group from a KHV laboratory exposure trial (Gilad et al., 2004). The 8 unexposed fish showed little anti-KHV activity at dilutions of 1:500 or greater while 8 fish surviving a KHV exposure had consistently higher O.D. values at all serum dilutions tested (Fig. 6). Sera from this same group of fish were used in western blots prepared to examine potential KHV proteins recognized by the serum antibodies.

Based upon examinations of the different populations of naturally and experimentally exposed koi to the KHV some general guidelines were established for O.D. values considered as indicating the presence of anti$\mathrm{KHV}$ antibodies in a given serum sample. At serum dilutions of $1: 2500$, O.D. values greater than $15 \%$ of the positive control (in our study O.D. value of approximately 0.18 and above) were considered as a strong indication of the presence of anti-KHV antibodies. Also, at this serum dilution potential cross reactions with anti-CyHV-1 antibodies is minimized.

\section{Western Blotting}

Twenty-one KHV proteins of $31 \mathrm{kDa}$ or larger were visible in Coomassie blue stained SDS-PAGE gels. After electrophoretic transfer from the gel to the PVDF membrane and blotting, 14 of the $21 \mathrm{KHV}$ virus proteins were visible by amido black total protein staining. Thirteen of the 14 proteins were recognized by serum from at least 1 of the 8 fish that were survivors of laboratory-induced KHV infections (Fig. 7). Five of the KHV proteins of $166,133,97,50$ and $43 \mathrm{kDa}$, were recognized by at least 3 fish and the $97 \mathrm{kDa}$ protein was recognized by all but one fish. Most sera collected from 8 juvenile koi injected with CyHV-1 8 wk prior did not react with KHV proteins (Fig. 7). However, serum from one fish reacted strongly with a protein of approximately 


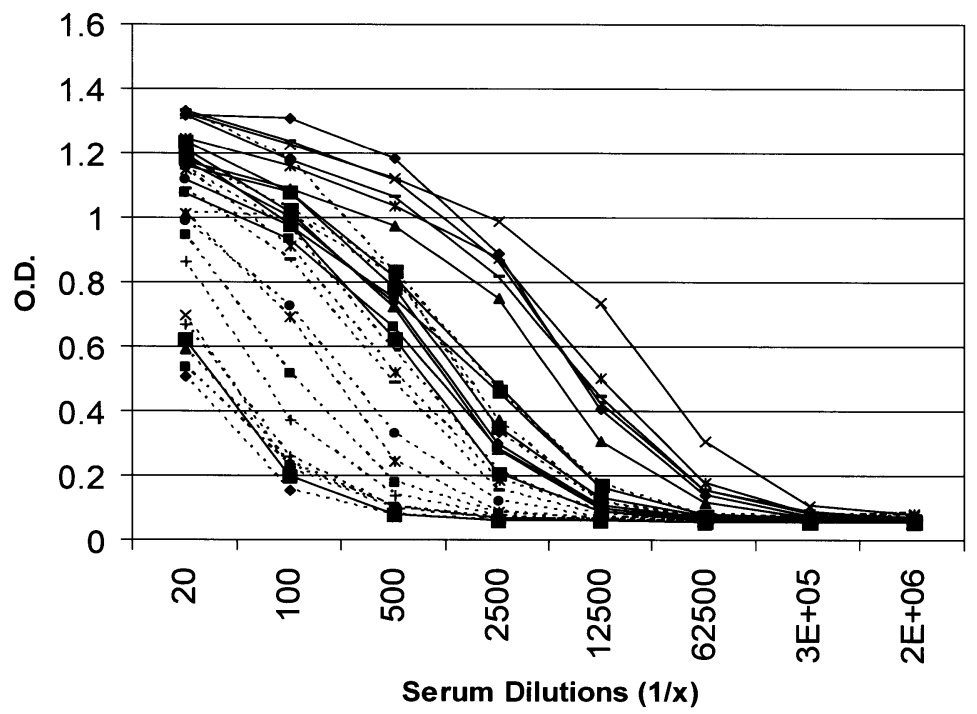

Fig. 5. Enzyme-linked immunosorbent assay (ELISA) detection of anti-koi herpesvirus (KHV) antibodies in the serum of a population (S2-1) of koi from a retailer (Supplier 2) that were examined 6 wk after recovery from a KHV outbreak. A serial titration of each individual serum is shown with KHV ( ) or CyHV-1 (.......) as coating antigen.

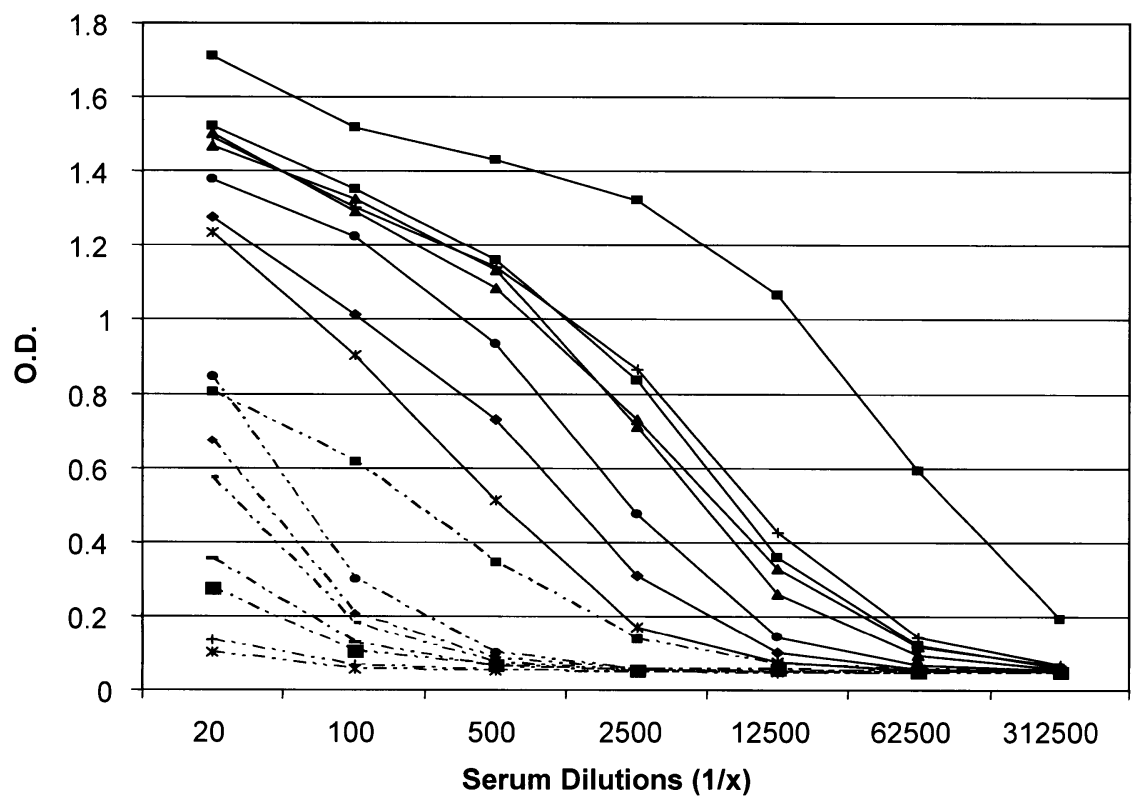

Fig. 6. Enzyme-linked immunosorbent assay (ELISA) detection of anti-koi herpesvirus (KHV) antibodies in the serum of a population (S4-1) of koi surviving experimentally-induced KHV disease. Koi were examined 64 days following initial exposure to the virus (—). An additional eight control koi not exposed to the virus are also show (-...-...).

$130 \mathrm{kDa}$ and a second fish sera recognized two proteins of a 170 and $56 \mathrm{kDa}$. Control koi serum failed to react with virus proteins of KHV or CyHV-1 (not shown).

Eleven CyHV-1 proteins were visible by amido black staining on PVDF following transfer from the SDS-PAGE gels. When these membranes were probed with serum from 8 individual CyHV-1 exposed fish 8 of the 11 proteins were recognized by at least 1 fish (Fig. 8). An additional 6 CyHV-1 proteins, not visible by amido black staining, were identified by probing with the anti-CyHV-1 sera. Serum from 8 koi surviving KHV infection recog- nized several CyHV-1 proteins ranging from 35 to over $200 \mathrm{kDa}$ but in most cases serum from individual fish recognized only one CyHV-1 protein and the size of that protein differed for each fish.

\section{Passive immunity trial}

A pooled serum sample from 10 fish surviving experimental KHV infections had high levels of anti-KHV antibodies as determined by ELISA (Fig. 9). In contrast, a serum pool from 10 fish from the same population but not exposed to KHV had low levels of 


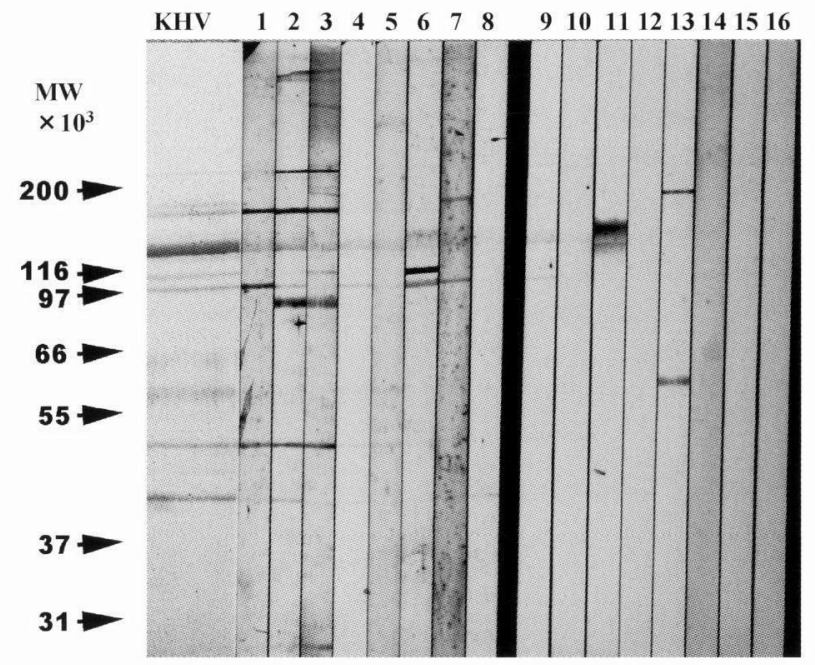

Fig. 7. Virion polypeptides of the herpesvirus (KHV) recognized by antibodies in the serum of koi recovering from experimental exposures (lanes 1-8) to KHV or following experimental exposures to Cyprinid herpesvirus 1 (lanes 9-16). Each lane represents serum from an individual fish.

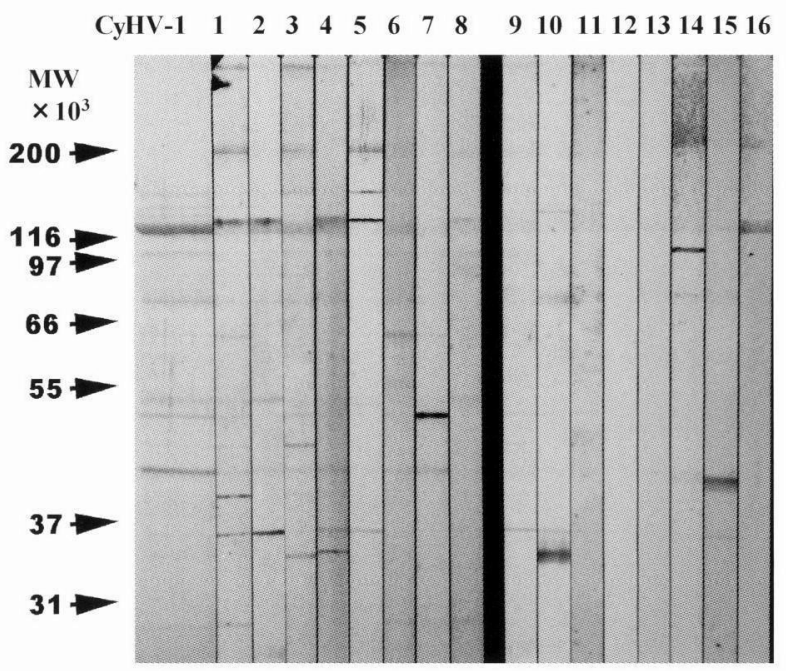

Fig. 8. Virion polypeptides of the Cyprinid herpesvirus 1 (CyHV-1) recognized by antibodies in the serum of koi following experimental exposures to Cyprinid herpesvirus 1 (lanes $1-8$ ) or recovering from experimental exposures (lanes 9-16) to KHV. Each lane represents serum from an individual fish.

activity. Intraperitoneal administration of serum with or without anti-KHV activity to groups of koi provided either partial or no protection from experimental exposures to KHV, respectively (Fig. 10). Koi administered serum with anti-KHV activity demonstrated a delayed onset and substantially reduced mortality $(40 \%)$ compared to koi administered control serum ( $80 \%$ ) by 12 days post virus exposure. Following a short cessation in mortality at day 10 to 12 post virus exposure among fish receiving the positive serum, a second mortality episode began resulting in a final cumulative mortality of $80 \%$. Fish

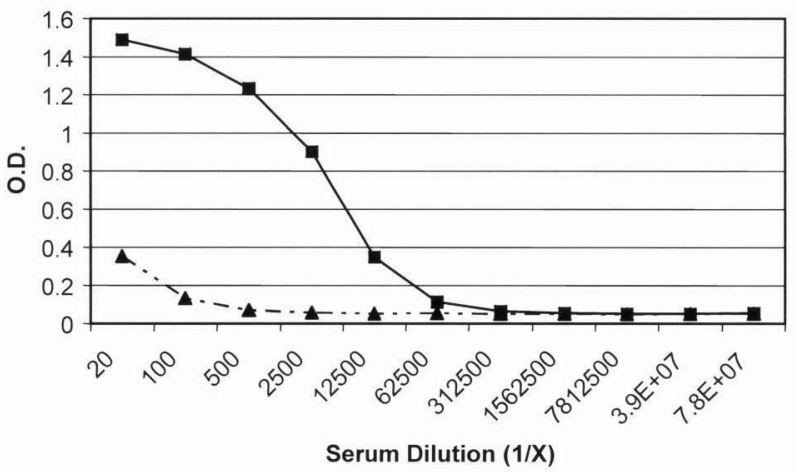

Fig. 9. Enzyme-linked immunosorbent assay (ELISA) detection of anti-koi herpesvirus (KHV) antibodies in a pooled serum sample from a population (S4-1) of koi following recovery from experimental exposures to $\mathrm{KHV}$. The serum was collected 64 days following initial virus exposure. A serial titration of the pooled serum from ten fish is shown (positive - $\mathbf{-}$ ) and ten additional koi from the same population not exposed to KHV (negative - $\mathbf{\Delta}$ ).

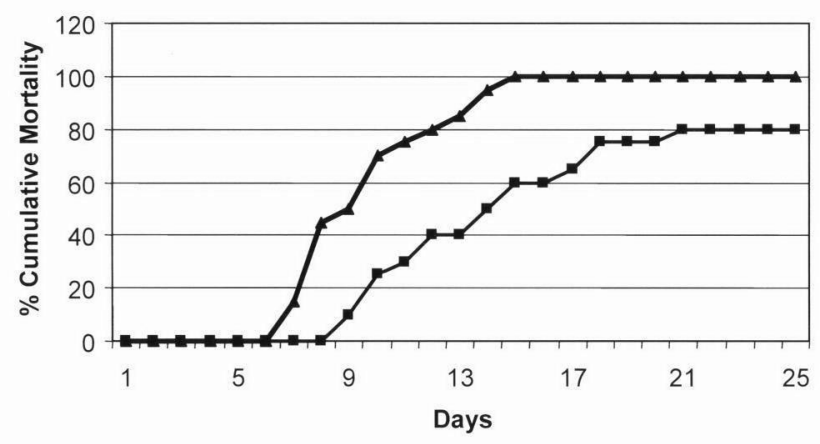

Fig. 10. Cumulative mortality following KHV exposures of juvenile koi receiving intraperitoneal injections with serum from koi surviving experimental KHV infections ( a) or serum from koi with no previous exposures to KHV (ム).

receiving the negative serum pool continued to die until the cumulative mortality reached $100 \%$ at 24 days post virus exposure. Virus isolations were positive from a total of 5 dead fish from each of the virus-exposed groups (negative or positive serum) examined at the peak of mortality. All other dead fish displayed the same external signs but were not examined for virus. There was no mortality in groups of koi not exposed to KHV.

\section{Discussion}

The presence of serum anti-KHV antibodies was detected by ELISA among populations of koi following experimental or natural exposures to the virus. Serum anti-KHV antibodies were detected in nearly all fish surviving at 42 to 47 days after losses due to naturally occurring outbreaks or experimentally induced KHV disease. High concentrations of anti-KHV antibodies in 
the serum of these koi were indicated by elevated O.D. values at serum dilutions as great as 1:62,500. One population of koi (S3-1) held in an aquarium receiving virus-free water $\left(21^{\circ} \mathrm{C}\right)$ also had similarly high anti-KHV antibody concentrations when examined 1 year from the last known exogenous contact with KHV. Examinations of serum from koi following natural and experimental infections with KHV by ELISA and western blotting demonstrated the potential for cross reactions with a second related herpes-like virus from cyprinid fish, CyHV1. These cross reactions were eliminated if sera were diluted to 1:2500 or greater. The passive administration of anti-KHV serum to naive koi failed to provide adequate protection to $\mathrm{KHV}$ challenge suggesting that both cellular and humoral components of the immune response are likely needed for immunity to KHV.

Fish that survive exposures to viruses whose life cycle involves systemic invasion of tissues most often produce anti-virus antibodies detected in the serum (Plumb 1973; Hattenberger-Badouy et al., 1989; Kibenge et al., 2002). These anti-virus antibodies can be detected by several methods including neutralization, complement fixation, co-agglutination or most commonly by ELISA (LaPatra, 1996). The first descriptions of anti-KHV antibodies detected by ELISA in koi serum were by Ronen et al. (2003). They utilized an ELISA to demonstrate that experimentally-infected koi developed serum anti-KHV antibodies that increased in concentration over time and which remained present in fish up to 50 days post virus exposure.

Our studies on four populations of koi provide additional insights into the presence of serum anti-KHV antibodies following experimental or natural exposures to KHV. Anti-KHV serum antibodies were generally absent in two populations of koi with no history of KHV disease (S1-1 and S1-2). In these populations we detected only 3 fish of a total of 81 examined that had O.D. values above $15 \%$ of the positive control (19$40 \%$ ). These positive responding fish may actually have represented low level exposure as later interviews with farm personnel indicated some movements of fish among ponds had occurred unknowingly. In contrast to the few low responding fish in S1-1 and S1-2 fish, a much higher prevalence of positive responding koi were found in a group of koi (S3-1) that had survived an outbreak of KHV disease and were then held for 1 year in a virus-free water source. In a population of koi from Supplier 1 (S1-3) a conversion from low to high prevalence of responders (anti-KHV antibodies found) coincided with an outbreak due to KHV (Fig. 2). Although serum samples were not available from a second population of koi from Supplier 2 (S2-1) before a KHV outbreak, samples examined 47 days later demonstrated that a majority of fish were high anti-KHV antibody responders (Fig. 2). As reported by Ronen et al. (2003), a high prevalence of anti-KHV antibody response was present in a population of koi (S4-1) following experimental exposures to KHV in the laboratory (Fig. 6). Our examination of these 4 koi populations demonstrated a good relationship between the presence of antiKHV antibody detected by ELISA and a history of exposure to natural or experimental sources of the virus.

Most studies of anti-herpesvirus antibodies in fish are from natural or experimental infections of channel catfish with Ictalurid herpesvirus 1 (IcHV-1). Plumb (1973) was the first to demonstrate that catfish recovering from natural outbreaks due to the virus contained serum anti-virus antibodies detected by neutralization assays. Later studies demonstrated that the concentrations of serum anti-IcHV-1 showed variability over time that was attributed to seasonal or other environmental factors including changing water temperatures (Amend and McDowell, 1984; Bowser and Munson, 1986; Hedrick and McDowell, 1987; Hedrick et al., 1987). An ELISA developed to detect both the presence of antiIcHV-1 serum antibodies in naturally occurring channel catfish populations and the kinetics of the response following experimental exposures has been described (Crawford et al., 1999). The prevalence of adult catfish with anti-IcHV-1 antibodies and the detection of DNA specific to IcHV-1 in the adults and progeny from such adults suggest that latent carriers exist with the capability to vertically transmit the virus (Wise et al., 1988; Boyle and Blackwell, 1991; Gray et al., 1999; Thompson et al., 2005).

Evidence from both natural and experimental exposures of koi to KHV suggests that latent infections or a carrier state may be established in fish recovering from initial infections (Gilad et al. 2004; Hedrick et al., 2005; K. Way, pers. comm.). That a second herpes-like virus from koi (CyHV-1) related to KHV can establish a latent and recrudescent infection has been demonstrated (Sano et al., 1985a, b, 1991). Several tissues of koi recovering from experimental exposures of CyHV-1 contain virus-specific DNA as detected by hybridization methods (Sano et al., 1993a). In addition, the association and recurrence of the characteristic "pox" lesions in cyprinid fish attributed to CyHV-1 is linked to environmental factors favorable to recrudescence of latent virus (Sano et al., 1985b, 1991; Sano et al., 1993b). That virus-specific DNA of KHV can persist in koi tissues for at least 64 days following initial virus exposure was demonstrated by Gilad et al. (2003). KHV may persist for even longer periods in koi or common carp in the absence of disease at lower water temperatures (e.g. $13^{\circ} \mathrm{C}$ ) and these infections may manifest as water temperatures rise with the changing season (Gilad et al., 2002). The lower temperatures most likely directly affect the ability of KHV to replicate efficiently in the fish rather than a strong immune response which would be expected to be functioning at less than optimal capacity at these water temperatures (Bly and Clem, 1992). With CyHV-1, low 
water temperature effects on the immune response in koi were cited as one key factor in the recurrence of the skin lesions common to carp pox (Sano et al., 1993b).

Most outbreaks of KHV disease are associated with movement of healthy appearing fish from sites known for presence of the virus which are then mixed with virus naive populations of koi or common carp (Gilad et al., 2002; Haenen et al., 2004; Sano et al., 2004). Although convincing laboratory transmission trials have yet to be reported, the epidemiologic associations between fish movements and virus outbreaks provides strong evidence that carriers and virus latentcy are characteristic of KHV infections. Investigations in several laboratories are now aimed at understanding these important aspects of the biology of KHV.

Recent genetic studies comparing KHV with two other cyprinid herpesviruses (CyHV-1 and 2) demonstrate they are group of closely related viruses (Waltzek et al., 2005, Hedrick et al., 2005). Initial genome sequencing of $\mathrm{KHV}$ and $\mathrm{CyHV}-1$ reveal they possess many similar genes and gene arrangements ( $T$. Aoki, pers comm., unpublished data). Related proteins or glycoproteins of CyHV-1 and KHV that are immunogenic in koi and common carp may interfere with estimates of specific anti-virus antibody levels. Evidence that such cross reacting antibodies are present in koi serum was demonstrated in reciprocal ELISA and western blot examinations of serum from koi infected or inoculated with CyHV-1 or KHV (Fig. 5 and 7). The western blot analyses under denaturing conditions suggested that only a few proteins are cross-reactive and the immunoreactivity may vary considerably between different fish. Proteins of 170,130 , and $56 \mathrm{kDa}$ of KHV were involved in some of the cross reactions with anti-CyHV-1 serum while $\mathrm{CyHV}-1$ proteins in the range of 200 to 35 $\mathrm{kDa}$ were involved with anti-KHV serum. At present, we are uncertain of the role of these viral proteins but they may represent key components of the virus envelop or capsid involved in potential anti-viral immunity. Due to the cross reactions observed between $\mathrm{KHV}$ and CyHV-1, we suggest using serum dilutions of $1: 2,500$ or greater in the ELISA. Under these conditions, the ELISA is able to effectively discriminate between antiKHV and anti-CyHV-1 antibodies (Fig. 5).

That anti-KHV antibodies develop following natural or experimental exposures to KHV have been shown in our current study and that of Ronen et al (2003). Ronen et al. (2003) also demonstrated that KHV infected koi subjected to thermal regimes were resistance to subsequent challenge and that these fish possessed high anti-KHV antibody levels by ELISA. Our passive immunity trial suggests that anti-KHV antibodies provide some but only minimal protection to acute KHV disease (Fig. 10). This result contrasts to previous studies with antiIcHV-1 serum that completely protected juvenile channel catfish from acute infections with IcHV-1 (Hedrick et al.,
1987). The pooled anti-KHV serum used in our trials was deemed to contain high levels of anti-virus antibodies. Considering the half-life of carp Ig at nearly 22 days (Overath et al., 1999) ample anti-KHV antibodies should have been present to provide a protective effect. That little protection was observed suggests that anti-KHV antibodies alone are insufficient and other immune mechanisms, including cell-mediated responses are required to provide complete protection to KHV challenge.

In conclusion, an ELISA is described that was effective in detecting anti-KHV antibodies in the serum of several populations of koi. Because samples for ELISA analysis can be taken nonlethally, they offer an alternative to current lethal sampling procedures. The presence of anti-KHV antibodies in the serum of koi or common carp in the absence of disease is a good indicator of prior exposure to the virus and thus the potential for risk of movement of the virus with antibody positive fish. However, more convincing studies linking antibody positive fish to transmission (carrier status) are needed. In the interim and prior to wide scale applications of vaccines that may complicate serological analyses, the ELISA provides additional information to evaluate potential risks of virus transmission when PCR or other virological methods fail to reveal evidence for KHV. Lastly, anti-KHV antibodies present in the serum administered to naive koi provide only a transient and incomplete protection from KHV challenge suggesting that development of effective resistance to $\mathrm{KHV}$ will most likely involve stimulation of cell- mediated immune responses.

\section{Acknowledgements}

Support for this research was provided in part by BARD under contract no. IS-3539-04CR and the California Department of Fish and Game. We wish to thank M. El-Matbouli, Ronit LaVie, Thomas Waltzek, Terry McDowell, Susan Yun and Kavery Mukkatira for their technical assistance.

\section{References}

Amend, D. F. and T. McDowell (1984): Comparison of various procedures to detect neutralizing antibody to the channel catfish virus in California brood channel catfish. Prog. Fish Cult., 46, 6-12.

Bowser, P. R. and A. D. Munson (1986): Seasonal variation in channel catfish virus antibody titers in adult channel catfish. Prog. Fish. Cult., 48, 198-199.

Boyle, J. and J. Blackwell (1991): Use of the polymerase chain reaction to detect latent channel catfish virus. $A m$. J. Vet Res., 52, 1965-1968.

Bly, J. E. and L. W. Clem (1992): Temperature and teleost immune functions. Fish Shellfish Immunol., 2, 159-171.

Bretzinger, A., T. Fischer-Scherl, M. Oumouma., R. Hoffmann and U. Truyen (1999): Mass mortalities in koi, Cyprinus carpio, associated with gill and skin disease. Bull. Eur. 
Assoc. Fish. Pathol., 19, 182-185.

Case, J. T., A. A. Ardans, D. C. Bolton and B. J. Reynolds (1983): Optimization of parameters for detecting antibodies against infectious bronchitis virus using an enzyme linked immunosorbent assay: Temporal response to vaccination and challenge with live virus. Avian Dis., 27, 196-210.

Crawford, S. A., Gardner, I. A. and R. P. Hedrick (1999): An enzyme-linked immunosorbent assay (ELISA) for detection of antibodies to channel catfish virus (CCV) in channel catfish. J. Aquat. An. Health 11, 148-153.

Gilad, O., S. Yun, K. B. Andree, M. A. Adkison, A. Zlotkin, H. Bercovier, A. Eldar and R. P. Hedrick (2002): Initial characteristics of koi herpesvirus and development of a polymerase chain reaction assay to detect the virus in koi, Cyprinus carpio koi. Dis. Aquat. Org., 48, 101-108.

Gilad, O., S. Yun, M. A. Adkison, K. Way, N. H. Willits, H. Bercovier and R. P. Hedrick (2003): Molecular comparison of isolates of an emerging fish pathogen, koi herpesvirus, and the effect of water temperature on mortality of experimentally infected koi. J. Gen. Virol., 84, 2661-2667.

Gilad, O., S. Yun, F. Zagmutt-Vergara, C. M. Leutenegger, H. Bercovier and R. P. Hedrick (2004): Concentrations of a herpes-like virus (KHV) in tissues of experimentally-infected Cyprinus carpio koi as assessed by real-time TaqMan PCR. Dis. Aquat. Org., 60, 179-187.

Gray, W. L., R. J. Williams, B. R. Griffin (1999): Detection of channel catfish virus DNA in latently infected catfish. J. Gen. Virol., 80, 1817-1822.

Gray, W. L., L. Mullis, S. E. LaPatra, J. M. Groff and A. Goodwin (2002): Detection of koi herpesvirus DNA in tissues of infected fish. J. Fish Dis., 25, 171-178.

Haenen, O. L. M., K. Way, S. M. Bergmann and E. Areil (2005): The emergence of koi herpesvirus and its significance to European aquaculture. Bull. Eur. Assoc. Fish Pathol., 24, 293-307.

Hattenberger-Baudouy, A. M., M. Danton, G. Merle, C. Torchy and P. de Kinkelin (1989): Serological evidence of infectious hematopoietic necrosis in rainbow trout from a French outbreak of disease. J. Aquat. An. Health, 1, 1126-134.

Hedrick, R. P. and T. McDowell (1987): Passive transfer of sera with antivirus neutralizing activity from adult channel catfish protects juveniles from channel catfish virus disease. Trans. Am. Fish. Soc., 116, 277-281.

Hedrick, R. P., J. M. Groff and T. McDowell (1987): Response of adult channel catfish to waterborne exposures to channel catfish virus. Prog. Fish. Cult., 49, 181-187.

Hedrick, R. P., G. D. Marty, R. W. Nordhausen, M. Kebus, H. Bercovier and A. Eldar (1999): An herpesvirus associated with mass mortality of juvenile and adult koi Cyprinus carpio. Fish Health Newsletter, Fish Health Section, American Fisheries Society, $27,7$.

Hedrick, R. P., O. Gilad, S. Yun, J. V. Spangenberg, G. D. Marty, R. W. Nordhausen, M. J. Kebus, H. Bercovier and A. Eldar. (2000): A herpesvirus associated with mass mortality of juvenile and adult koi, a strain of a common carp. J. Aquat. Anim. Health, 12, 44-57.

Hedrick, R. P., O. Gilad, S. C. Yun, T. S. McDowell, T. B. Waltzek, G. O. Kelley and M. A. Adkison (2005): Initial isolation and characterization of a herpes-like virus (KHV) from koi and common carp. Bull. Fish. Res. Agen., Supplement No. 2, 1-7.

Hutoran, M., Ronen, A., Perelberg, A., M. Ilouze, A. Dishon, I. Bejerano, N. Chen and M. Kotler (2005). Description of an as yet unclassified DNA virus from diseased Cyprinus carpio species. J. Virol., 79 (in press).

Kibenge, M. T., B. Opazo, A. H. Rojas and F. S. Kibenge (2002): Serological evidence of infectious salmon anaemia virus (ISAV) infection in farmed fishes, using an indirect enzyme-linked immunosorbent assay (ELISA). Dis. Aquat. Org., 51, 1-11.

LaPatra, S. E. (1996): Characterization of the humoral response of rainbow trout to infectious hematopoietic necrosis virus. Ann. Rev. Fish Dis., 6, 15-28.

Perelberg, A., M. Smirnov, M. Hutoran, A. Diamant, Y. Bejerano and M. Kotler. (2003): Epidemiological description of a new viral disease afflicting cultured Cyprinus carpio in Israel. Is. J. Aqua. - Bamidgeh, 55, 5-12.

Overath P., J. Haag, M. G. Mameza and A. Lischke (1999): Freshwater fish trypanosomes: definition of two types, host control by antibodies and lack of antigenic variation. Parasitology, 119, 591-601.

Pikarsky, E., A. Ronen, J. Abramowitz, B. Levavi-Sivan, M. Hutoran, Y. Shapira, M. Steintz, A. Perelberg, D. Soffer and M. Kotler (2004). Pathogenesis of acute viral disease induced in fish by carp interstitial nephritis and gill necrosis virus. J. Virol., 78, 9544-9551.

Plumb, J. A. (1973): Neutralization of channel catfish virus by serum of channel catfish. J. Wild. Dis., 9, 324-330.

Ronen, A., A. Perelberg, J. Abramowitz, M. Hutoran, S. Tinman, I. Bejerano, M. Steinitz and M. Kotler (2003): Efficient vaccine against the virus causing a lethal disease in cultured Cyprinus carpio. Vaccine, 21, 4677-4684.

Rombout, J., N. Taverne, M. van de Kamp and A. J. TaverneThiele (1993): Differences in mucus and serum immunoglobulin of carp (Cyprinus carpio L.). Dev. Comp. Immuno., 4, 309-317.

Sano, M., T. Ito, J. Kurita, T. Yanai, N. Watanabe, M. Satoshi and T. lida (2004): First detection of koi herpesvirus in cultured common carp Cyprinus carpio in Japan. Fish Pathol., 39, 165-167.

Sano, N., M. Morwake, R. Hondo and T. Sano (1993a): Herpesvirus cyprini: a search for viral genome in infected fish by in situ hybridization. J. Fish Dis., 16, 495-499.

Sano N., M. Moriwake and T. Sano (1993b): Herpesvirus cyprinid: Thermal effects on pathogenicity and oncogenicity. Fish Pathol., 28, 171-175.

Sano, T., H. Fukuda, M. Furukawa, H. Hosoya and Y. Moriya (1985a): A herpesvirus isolated from carp papilloma in Japan. Fish Shell. Pathol., 32, 307-311.

Sano, T., H. Fukuda and M. Furukawa (1985b): Herpesvirus cyprini: biological and oncogenic properties. Fish Pathol., 10, 381-388.

Sano, T., N. Morita, N. Shima and M. Akimoto (1991): Herpesvirus cyprini: lethality and oncogenicity. J. Fish Dis., 14, 533-543.

Thompson, D. J., L. H. Khoo, D. J. Wise and L. A. Hanson (2005): Evaluation of channel catfish virus latency on fingerling production farms in Mississippi. J. Aquat. Anim. Health, (in press)

Tu, C., M-C. Weng, J-R. Shiau and S-Y. Lin (2004): Detection of koi herpesvirus in koi Cyprinus carpio in Taiwan. Fish Pathol., 39, 109-110.

Waltzek, T. B, G. O. Kelley, D. M. Stone, K. Way, L. A. Hanson, H. Fukuda, A. J. Davison, T. Aoki and R. P. Hedrick (2005): Koi herpesvirus represents a third cyprinid herpesvirus (CyHV-3) in the family Herpesviridae. J. Gen. Virol., (in press).

Wise, J. A., S. F. Harrell, R. L. Busch and J. A. Boyle (1988): Vertical transmission of channel catfish virus. $A m$. J. Vet. Res., 49, 1506-1509.

Yuasa, K., M. Sano, J. Kurita, T. Ito and T. lida (2005): Improvement of a PCR method with the Sph I-5 primer set for the detection of koi herpesvirus (KHV). Fish Pathol., 40, 3739. 